\title{
QUEEN'S
UNIVERSITY
BELFAST
}

\section{Post-slaughter changes in ATP metabolites, Reducing and phosphorylated sugars in chicken meat}

Aliani, M., Farmer, L. J., Kennedy, J. T., Moss, B. T., \& Gordon, A. (2013). Post-slaughter changes in ATP metabolites, Reducing and phosphorylated sugars in chicken meat. Meat Science, 94(1), 55-62.

https://doi.org/10.1016/j.meatsci.2012.11.032

\section{Published in:}

Meat Science

\section{Document Version:}

Peer reviewed version

Queen's University Belfast - Research Portal:

Link to publication record in Queen's University Belfast Research Portal

\section{Publisher rights}

(C) 2015, Elsevier. Licensed under the Creative Commons Attribution-NonCommercial-NoDerivatives 4.0 International

http://creativecommons.org/licenses/by-nc-nd/4.0/which permits distribution and reproduction for non-commercial purposes, provided the author and source are cited.

\section{General rights}

Copyright for the publications made accessible via the Queen's University Belfast Research Portal is retained by the author(s) and / or other copyright owners and it is a condition of accessing these publications that users recognise and abide by the legal requirements associated with these rights.

\section{Take down policy}

The Research Portal is Queen's institutional repository that provides access to Queen's research output. Every effort has been made to ensure that content in the Research Portal does not infringe any person's rights, or applicable UK laws. If you discover content in the Research Portal that you believe breaches copyright or violates any law, please contact openaccess@qub.ac.uk. 


\section{Accepted Manuscript}

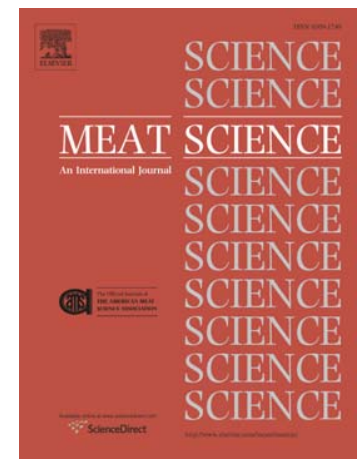

Post-slaughter changes in ATP metabolites, reducing and phosphorylated sugars in chicken meat

Michel Aliani, Linda J. Farmer, James T. Kennedy, Bruce W. Moss, Alan Gordon

PII: $\quad$ S0309-1740(12)00393-2

DOI: $\quad$ doi: $10.1016 / j . m e a t s c i .2012 .11 .032$

Reference: $\quad$ MESC 5892

To appear in: $\quad$ Meat Science

Received date: 5 August 2012

Revised date: $\quad 6$ November 2012

Accepted date: 13 November 2012

Please cite this article as: Aliani, M., Farmer, L.J., Kennedy, J.T., Moss, B.W. \& Gordon, A., Post-slaughter changes in ATP metabolites, reducing and phosphorylated sugars in chicken meat, Meat Science (2012), doi: 10.1016/j.meatsci.2012.11.032

This is a PDF file of an unedited manuscript that has been accepted for publication. As a service to our customers we are providing this early version of the manuscript. The manuscript will undergo copyediting, typesetting, and review of the resulting proof before it is published in its final form. Please note that during the production process errors may be discovered which could affect the content, and all legal disclaimers that apply to the journal pertain. 


\section{Post-slaughter changes in ATP metabolites, reducing and phosphorylated sugars in chicken meat}

Michel Aliani $^{a, b, c}$, Linda J Farmer ${ }^{*, a, b}$, James T Kennedy ${ }^{a}$, Bruce W Moss $^{a, b}$, Alan Gordon $^{a}$

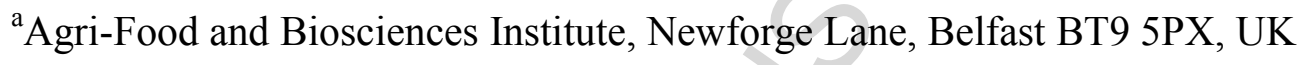

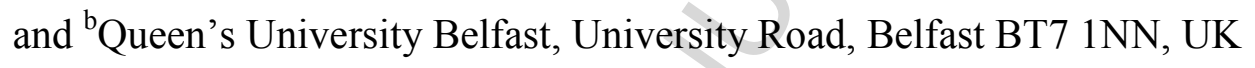

* To whom corresponding should be addressed. Telephone: +44 (0)2890 255342. Fax: +44 (0)2890 255006. Email: linda.farmer@afbini.gov.uk

${ }^{\mathrm{c}}$ Now at Human Nutritional Sciences, University of Manitoba, Winnipeg, Canada, R3T 2N2 


\section{Abstract}

The formation of $\mathrm{ATP}^{1}$ breakdown products in chicken $M$. pectoralis major post-slaughter is reported. The concentrations of metabolites were followed in chicken breast throughout the carcass processing post-slaughter and during chilled storage. The concentration of glucose remains similar throughout the period while that of glucose-6-phosphate decreases linearly. Glucose and glucose-6-phosphate concentration were inversely related to the $\mathrm{pHu}$ of the breast meat throughout chilled storage. Rapid post-mortem glycolysis and high $\mathrm{pHu}$ values suggest the occurrence of stress at and pre-slaughter. While ATP, ADP and AMP were rapidly broken down, the concentration of IMP rose rapidly and remained high. Concentrations of inosine, ribose and hypoxanthine increased gradually post-slaughter but an initial increase in ribose phosphate was not sustained. Most of the potential ribose present in chicken meat, believed to be important for flavor formation, remains bound in the form of inosine and IMP. There is evidence that additional breakdown pathways for ribose and ribose-5-phosphate may deplete the concentrations of these precursors.

Keywords: Ribose; Glucose; Nucleotides; Chicken; Post-slaughter; Chilled storage.

1 ATP: adenosine 5'-triphosphate; ADP: adenosine 5'-diphosphate; AMP: adenosine 5'-monophosphate; IMP: inosine 5'-monophosphate 


\section{Introduction}

Post-mortem changes that occur in the conversion of muscle to meat not only alter some of its biochemical and physical properties but also play an important role in improving its acceptability as food (Pearson, 1987). The nature of these changes and their consequences for meat have been reviewed (Greaser, 1986; Pearson, 1987). Many of the biochemical pathways involved during slaughter and the post-mortem aging period in skeletal muscles were elucidated some years ago and result in the formation of sugars (Lilyblade \& Peterson, 1962), organic acids (Bodwell, Pearson, \& Spooner, 1965), peptides and free amino acids (Parrish, et al., 1969), and metabolites of adenosine nucleotides (Dannert \& Pearson, 1967; Davidek \& Khan, 1967). These chemical modifications in the ageing meat result in a pool of taste compounds and flavor precursors; these latter react during cooking to form the volatile components of flavour. Recently, a new hypothesis has been proposed by Ouali et al., (2006) suggesting the existence of an early phase, named "apoptosis", prior to traditional steps involved in the conversion of muscle to meat.

The role of IMP for the generation of meat odor and flavor has been demonstrated both in model systems and sensory studies (Farmer, Hagan, \& Paraskevas, 1996; Mottram, 1994). Ribose-5phosphate also causes important changes in beef odor, while glucose and glucose-6-phosphate cause much smaller effects (Farmer, Hagan, \& Paraskevas, 1998; Mottram, 1998). The addition of small quantities of ribose to raw beef and chicken has been shown to increase the quantities of key odor compounds, as well as meaty and roasted notes, especially in chicken (Aliani \& Farmer, 2005b; Farmer, et al., 1996). In fact, ribose has been identified as a key flavor precursor of cooked chicken meat and as little as 2-4 fold addition to raw chicken prior to cooking increased desirable odor and flavor of cooked chicken (Aliani \& Farmer, 2005b). It seems likely that ribose plays a greater role in the formation of flavour in chicken than in the red meats due to the proportionately lower concentrations of six carbon sugars in chicken (Farmer, Kennedy, \& Hagan, 2009).

Glucose and glucose-6-phosphate are formed by the glycogenolysis and glycolysis pathways, respectively, while IMP, ribose and ribose-5-phosphate have been reported to derive from the ATP breakdown pathway (Lee \& Newbold, 1963). The progress of these pathways was the subject of 
biochemical investigations in the 1960s (Davidek \& Khan, 1967; De Fremery, 1966; Terasaki, Kajikawa, Fujita, \& Ishi, 1965). However, these studies did not investigate the changes in concentrations of sugars such as ribose and ribose phosphate, or how these pathways may contribute to the availability of flavor precursors in the raw meat. More recent studies have determined a range of sugars in beef during ageing (Koutsidis, et al., 2008).

The work described in this paper aims to investigate how time post-slaughter (both during processing and shelf-life) affects the formation of ribose and other potential metabolites of ATP in raw meat. This knowledge will increase understanding of the time post-slaughter and storage conditions needed to reach the maximum concentration of flavor precursors for development of desirable cooked chicken flavor.

\section{Materials and methods}

\subsection{Chemicals}

D-ribose-5-phosphate disodium salt, D-glucose-6-phosphate disodium salt hydrate, alpha-Dlactose monohydrate, alpha-L-rhamnose, D-ribose, D-glucose, D-fructose, D-mannose, D-fructose6-phosphate disodium salt dehydrate, D-mannose-6-phosphate disodium salt hydrate, D-ribulose, Dribulose-5-phosphate disodium salt, D-xylulose, D-xylulose-5-phosphate sodium salt, adenosine 5' triphosphate (ATP), adenosine $5^{\prime}$-diphosphate (ADP), adenosine $5^{\prime}$-monophosphate (AMP), inosine 5'-monophosphate disodium salt (IMP), hypoxanthine (Hx), inosine, purine, cytidine and tetrazolium blue (3,3' -(3,3' -dimethoxy(1,1' '-biphenyl)-4,4' -diyl)-bis(2,5-diphenyl-2H-tetrazolium)dichloride) were purchased from Sigma-Aldrich Ltd. (Poole, UK). Alkaline phosphatase (EC 3.1.3.1) from bovine intestinal mucosa, Dowex 50WX4 resin (strongly acidic cation, 200-400 dry mesh), Dowex WGR-2 resin (weakly basic anion, 20-50 mesh), Dowex Marathon WBA resin (weakly basic anion, 25-50 wet mesh), hexamethyldisilazane, chlorotrimethylsilane, cyclohexane and dimethyl sulphoxide were also purchased from Sigma-Aldrich Ltd. Analytical-grade chloroform and methanol (high-performance liquid chromatography (HPLC) grade) were from Lab-Scan Ltd. (Dublin, Ireland), perchloric acid from May \& Baker Ltd. (Dagenham, UK) and HPLC grade ethanol 
and acetonitrile from Fisher Scientific UK Ltd. (Loughborough UK). Potassium hydroxide, potassium dihydrogen orthophosphate, potassium tartrate, glycine, magnesium chloride 6-hydrate, sodium acetate trihydrate, sodium carbonate, sodium hydroxide, hydrochloric acid were also from Fisher Scientific UK Ltd. All water used in the processes was from an Elgastat Option 4 water purification unit (Elga Ltd., High Wycombe, UK).

\subsection{Chicken meat}

Whole chilled chickens were provided by one commercial poultry supplier and, within an experiment, were from the same batch and farm. They were a standard Ross 308 genotype and were reared, slaughtered and processed under commercial conditions. A brief outline of the processing procedure is shown in Figure 1. Two experiments were designed to investigate the effect of time and temperature on the formation of ATP-related compounds in chicken breast post-slaughter. Experiment 1 was designed primarily to study the changes in ATP related compounds as the breast muscle went in to rigor, whilst Experiment 2 studied the changes in metabolites post rigor. For Experiment 2 the chickens were supplied overwrapped as roasting chickens for the retail market. These two experiments were conducted on different occasions with Experiment 1 conducted in summer and Experiment 2 in winter.

\section{[Figure 1]}

\subsubsection{Experiment 1. Post-slaughter period (15-120 minutes post-slaughter).}

Chickens were slaughtered using electrical stunning and exsanguination, plucked and eviscerated using the standard commercial process (Figure 1). The birds were hanged from their legs on a moving chain and all steps were conducted automatically within a plant with temperature control as shown in Figure 1. The air temperature was $15{ }^{\circ} \mathrm{C}$ for 13 minutes, $7-8{ }^{\circ} \mathrm{C}$ "pre chill" for 30 minutes and $1-2{ }^{\circ} \mathrm{C}$ "chill" for 2 hours. A total of 18 chickens were sampled, six at each of three different stages (A, B and C, Figure 1), at approximately 7, 25 and 115 minutes post-slaughter. Chicken carcasses were brought to an in-plant laboratory within three minutes, and samples taken and frozen within the following five minutes. This gave sample freezing times post-slaughter of ca. 15, 33 and 123 minutes. One breast muscle (M. pectoralis major) was removed, a strip of chicken muscle was 
cut $(1 \mathrm{~cm}$ wide) from the closest edge to the keel bone and divided into approximately $3 \mathrm{~g}$ portions. Duplicate samples were immediately placed in plastic clipper-bags (Somerville Packing, Lisburn, Northern Ireland), sealed and placed in a polystyrene insulated box and covered with dry ice at -65 ${ }^{\circ} \mathrm{C}$. Samples were held at dry ice temperature until return to the Agri-Food and Biosciences Institute (approximately 40 minutes after the last sample was collected) where they were transferred to storage at $-80^{\circ} \mathrm{C}$ until use.

\subsubsection{Experiment 2. Chilled storage (28-200 hours post-slaughter).}

Six individual standard chickens were sampled at "stage C" (after chilling) and transferred from the poultry plant to the laboratory (approximately 40 minutes) in a container filled with ice $\left(0{ }^{\circ} \mathrm{C}\right)$. They were then held at $4 \pm 1{ }^{\circ} \mathrm{C}$ until the end of the experiment (200 hours), which was selected to be similar in time to the end of commercial shelf life, ca. 8 days. Samples of breast meat were taken at 4, 28, 55, 100, 150 and 200 hours post-slaughter. At each of these sampling times, samples (each of $3 \mathrm{~g}$ ) were taken with a scalpel from one breast from each chicken, avoiding cut surfaces from previous sampling dates. A small preliminary study had indicated that the most variation in concentrations of sugars occurred in the anterior and posterior portions of the breast, whereas samples from the central portion had generally similar concentrations of sugars. Therefore, samples were taken from the mid portion as show in Figure 2. A systematic sampling design, using a grid of 12 sampling sites A to L (Figure 2), was used to avoid bias due to any differences between sampling sites; sampling sites A to L were balanced across chickens and sampling date.

The $\mathrm{pH}$ was recorded on the excised site of the chicken breast at each sampling time, using a LanceFET probe with stainless steel tip (Sentron, The Netherlands). At each sampling, the cling film overwrap and skin were folded back to expose the breast meat and then used to cover the muscle until the next sampling time. Samples were vacuum packed and kept at $-80{ }^{\circ} \mathrm{C}$ until needed for analysis. Ultimate $\mathrm{pH}(\mathrm{pHu})$ was taken as the mean value of the $\mathrm{pH}$ determinations at $4-55 \mathrm{~h}$ postslaughter, as there was no change over this period.

\section{[Figure 2]}

\subsection{Methods of analysis}




\subsubsection{Quantification of reducing and phosphorylated sugars in raw chicken}

In Experiment 1, the reducing and phosphorylated sugars were extracted using ethanol/water, followed by analysis by post-column derivitization HPLC, with an enzymatic reaction to convert phosphate sugars to their parent sugars (Aliani \& Farmer, 2002). The ribonucleotide related compounds were acid extracted and analysed as described by Aliani and Farmer (2005a).

In Experiment 2, a perchloric acid extraction method modified from Aliani and Farmer (2005a) was used and sugars, sugar phosphates and ribonucleotide related compounds were analysed in the resultant sample extract. The method was amended between the two experiments to facilitate a common extraction procedure for sugars and nucleotides. This enabled one extract to be used for all these analytes, economising on chemicals and time. Each sample (3g) of raw chicken was placed in a 50-ml centrifuge tube (Apex, Alpha Laboratories, Eastleigh, UK), and 0.5ml aliquots of rhamnose $20 \mathrm{mM}$ and cytidine $10 \mathrm{mM}$ added as internal standards for sugar and ribonucleotide related analyses, respectively. The samples were homogenized (Ika Ultra-Turrax T25, Werke, Germany) with 6ml of perchloric acid $(0.6 \mathrm{M})$ and deionised water $(1.0 \mathrm{ml})$ for $2 \mathrm{~min}$ at full speed (Ika Ultra-Turrax T25, Werke, Germany) and centrifuged at $3000 \mathrm{~g}$ for $15 \mathrm{~min}$ at $4{ }^{\circ} \mathrm{C}$ (Mistral 3000i MSE, UK). The supernatant solution was retained and neutralized with potassium hydroxide $(\sim 0.8 \mathrm{ml}$ of $4 \mathrm{M})$, centrifuged again at $3000 \mathrm{~g}$ for $15 \mathrm{~min}$ before removing the precipitated potassium perchlorate salt by filtration through a Whatman No. 54 filter paper. The aqueous filtrate was stored at $4{ }^{\circ} \mathrm{C}$, if analysed within the next $24 \mathrm{~h}$, or at $-80{ }^{\circ} \mathrm{C}$ for later analysis. An aliquot $(3 \mathrm{ml})$ of the sample extract (ca. $\left.9 \mathrm{ml}\right)$ was resin treated to remove any interfering compounds before glucose and ribose sugars were analysed as described previously (Aliani \& Farmer, 2005a), except that the Dowex Anion WGR-2 resin was replaced by Marathon WBA ion exchange resin. The analysis of phosphorylated sugars by enzymatic treatment was conducted on a second aliquot $(1.5 \mathrm{ml})$ of sample extract (Aliani \& Farmer, 2002) except that the glycine buffer $\left(50 \mathrm{mM}\right.$, containing $\left.\mathrm{MgCl}_{2} 0.5 \mathrm{mM}\right)$ was replaced with sodium carbonate buffer $\left(50 \mathrm{mM}\right.$, containing $\left.\mathrm{MgCl}_{2} 0.5 \mathrm{mM}\right)$ at $\mathrm{pH} 9.3$ to enhance peak separation. The sugar analyses for Experiment 2 were carried out using a Dionex HPLC system (model DX500; Dionex Corp., Surrey, UK) equipped with a CarboPac PA1 anion-exchange analytical column (Dionex P/N 
35391; 250 X 4 mm i.d.) preceded by a similar guard column (Dionex P/N 43096; 4 X 50 mm), an AS50 autosampler, a GS50 gradient pump equipped and an ED50 pulsed electrochemical detector. The ED50 pulsed electrochemical detector was equipped with a gold electrode and an $\mathrm{Ag} / \mathrm{AgCl}$ reference electrode. The wave form parameters used were as follows: (wave form $=0.00 \mathrm{Sec}: 0.05$ $\mathrm{mV}, 0.20 \mathrm{Sec}$ : integration $=$ begin, $0.40 \mathrm{Sec}$ : integration $=$ end, $0.41 \mathrm{Sec}: 0.06 \mathrm{mV}, 0.60 \mathrm{Sec}: 0.06$ $\mathrm{mV}, 0.61 \mathrm{Sec}:-0.15 \mathrm{mV}, 1 \mathrm{Sec}:-0.15 \mathrm{mV}$ ). The system was controlled by a HPLC Chromoleon software (Windows version, 6.30). The two eluents, I: deionized water prepared using a water purification unit (Elgastat option 4, Elga Labwater, UK) and II: $200 \mathrm{mM} \mathrm{NaOH}$ in deionized water were prepared as specified by Dionex Ltd (20). The elution program for separation of sugars was: 015 mins, I (10\%): II (90\%), $0.7 \mathrm{ml} \mathrm{min}^{-1}$. The injection volume was $25 \mu \mathrm{L}$.

Standard solutions of glucose, ribose and rhamnose were analysed separately and as spiked additions to the extract to help confirm the identity of the sugars analyzed. In addition, the recovery of each sugar from the raw chicken meat was determined by analyzing five portions (3g) of homogenized chicken muscle both with and without spikes containing ribose (1mg), glucose (1.6mg), ribose-5-phosphate $(0.5 \mathrm{mg}$ disodium salt) and glucose-6-phosphate (0.6mg disodium salt) in $0.25 \mathrm{ml}$ of water.

\subsubsection{Confirmation of identity of reducing and phosphorylated sugars}

Identification of sugars and sugar phosphates was further confirmed by GC-MS with sample aliquots being lyophilized and derivatised using the method developed by Leblanc \& Ball (1977). They were analysed using a Hewlett Packard 6890 gas chromatograph linked to a 5973A mass selective detector controlled by Chemstation software. Samples $(1 \mu 1)$ were injected onto a Varian CP-SIL 19CB capillary column $(25 \mathrm{~m} \times 0.25 \mathrm{~mm} \times 0.2 \mu \mathrm{m})$ or Agilent HP-Ultra $(12 \mathrm{~m} \times 0.2 \mathrm{~mm} \times$ $0.33 \mu \mathrm{m}$ ) employing a split ratio of $10: 1$. The injector port was maintained at $250{ }^{\circ} \mathrm{C}$, the transfer line at $270{ }^{\circ} \mathrm{C}$. The oven temperature was held at $100^{\circ} \mathrm{C}$ for 1 minute and then ramped at $10^{\circ} \mathrm{C} \mathrm{min}^{-1}$ to $279^{\circ} \mathrm{C}$ and held at that temperature for 11 minutes. Identification was confirmed by comparison of the retention time and mass spectrum with the authentic compounds (Sigma-Aldrich, Poole, UK).

\subsubsection{Quantification of ribonucleotides and related compounds}


Post-slaughter samples from the two experiments were subjected to analysis for ATP-related substances. ATP, ADP, AMP, IMP, inosine and hypoxanthine were extracted using the acid extraction method described earlier. The sample extracts $(2 \mathrm{ml})$ were analysed by reverse phase HPLC using a Thermo-Separations HPLC system. For Experiment 1, a Prodigy ODS-3 HPLC

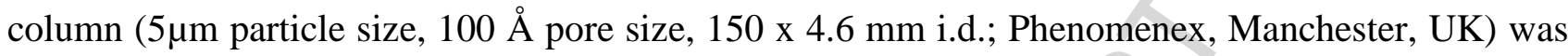
used with a Prodigy ODS-3 guard column ( $3 \mu \mathrm{m}$ particle size, $100 \AA$ pore size, $30 \mathrm{~mm}$ x $4.6 \mathrm{~mm}$ i.d.) also from Phenomenex and the elution with methanol/water (60:40) and aqueous $\mathrm{KH}_{2} \mathrm{PO}_{4}$ $(0.02 \mathrm{M}, \mathrm{pH} 5.5)$ using gradient elution and UV detection at $254 \mathrm{~nm}$, as described previously (Aliani

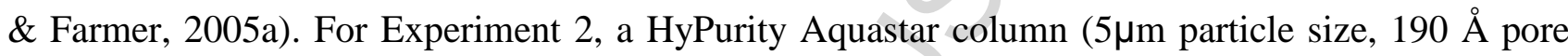
size, 150 X 4.6mm i.d.; Thermo Electron Corporation, Manchester UK) connected to a Phenomenex Securityguard guard column with a C18 3X4mm ID cartridge was used. An injection of sample extract $(20 \mu \mathrm{l})$ was eluted with an isocratic mobile phase $\mathrm{KH}_{2} \mathrm{PO}_{4}(50 \mathrm{mM})$ prepared with $\mathrm{HPLC}$ grade water, $\mathrm{pH}$ adjusted to 2.5 by dropwise addition of hydrochloric acid $(0.5 \mathrm{M})$ and filtered using $0.2 \mu \mathrm{m}$ cellulose nitrate membrane filters (Whatman) prior to use. The flow rate was $1 \mathrm{ml} \mathrm{min}^{-1}$ with a total run time of 30 minutes and UV detection at $254 \mathrm{~nm}$.

The identity of each of the ribonucleotides and related compounds was confirmed by comparison with standard solutions of ATP, ADP, AMP, IMP, inosine, hypoxanthine and cytidine, both analysed individually and as spiked additions to the extracts, using both HPLC columns referred to above.

\subsubsection{Measurement of $\mathrm{pH}$ and temperature post-slaughter}

Further information on the $\mathrm{pH}$ and internal temperatures of chickens taken from the same processing line at different times post-slaughter was obtained on a separate occasion. The $\mathrm{pH}$ and temperature measurements were conducted at the thickest part of the chicken breast (approx. one third down its length from the anterior end), using a LanceFET probe with stainless steel tip (Sentron, The Netherlands) inserted $10 \mathrm{~mm}$ into the muscle. Measurements were made on separate groups of six individual chickens sampled from the production line at six time-points between 2 and 115 minutes post-slaughter.

\subsection{Statistical Analyses.}


Analysis of variance was used to determine whether there were significant differences between time points and whether these relationships were linear in the case of Experiment 1. For Experiment 2, where more time points were available, the same analysis was used to determine if the relationship was linear or quadratic. All analyses were carried out using the statistical package GenStat (version 11). Correlations between metabolite concentrations and $\mathrm{pHu}$ were conducted using a simple Pearson's correlation.

\section{Results}

The recoveries for sugars and sugar phosphates differed between the methods used for Experiment 1 and 2. The method used for Experiment 1 gave average recoveries of 93, 90, 64 and 93\% for glucose, ribose, glucose-6-phosphate and ribose-5-phosphate, respectively. The reproducibility is illustrated by the coefficients of variation $(n=6)$ for these compounds, which were 5, 1, 10 and 4\%, respectively. The method used for Experiment 2 gave recovery levels of 114, 109, 107 and $113 \%$ for the same compounds respectively. The coefficient of variation $(n=5)$ was $3 \%$ for both glucose and ribose and 39 and 36\% respectively for glucose-6-phosphate and ribose-5phosphate. Thus, the method used in Experiment 2 gave an improved recovery for glucose-6phosphate but the repeatability for phosphorylated sugars was less good than for Experiment 1 . The methods for ribonucleotides and related compounds were the same for both Experiments and the recoveries were 87, 104, 94, 75, 63 and 99\% for IMP, inosine, hypoxanthine, ATP, ADP and AMP, respectively. Coefficients of variation $(n=5)$ for these compounds were $14,4,14,8,21$ and $3 \%$, respectively. The results presented for these analyses are corrected for recoveries and are, therefore, comparable.

Table 1 (Experiment 1) provides information on the extent of breakdown of ATP and its metabolites post-slaughter up to and including chilling. These results show that there are relatively few statistically significant changes in metabolites prior to chilling. Only hypoxanthine and ribose showed significant increases with time. IMP is the most abundant metabolite but remains relatively 
constant in concentration, possibly because its rate of formation and breakdown remain balanced during this early period post-slaughter.

\section{[Table 1]}

Table 2 (Experiment 2) follows the breakdown of ATP metabolites throughout the potential fresh shelf-life of six chickens, held at refrigeration temperatures from 4 to 200 hours. Many more statistically significant changes in metabolites were observed in Experiment 2 than Experiment 1 (Table 2), with loss of early metabolites and formation of the later ones. Only the concentration of glucose was unaffected by chilled storage. The changes in glucose and glucose phosphate, then ATP and its breakdown products, will be discussed in turn. The $\mathrm{pH}$ of the breast meat from these chickens, recorded at each of the times when analysed are also shown in Table 2.

\section{[Table 2]}

\section{Discussion}

There were consistent differences between the data from the two experiments (Table 1 and 2). In general, the variation observed between individual chickens was much greater in Experiment 1 than Experiment 2, which partly explains the fewer significant differences in Experiment 1. This variability was probably due to the sampling of chickens from the processing line at a time of rapidly changing biochemistry, before glycolysis was complete or rigor mortis had occurred. The sum of all the base-containing compounds, (ATP, ADP, AMP, IMP, inosine and Hx) remains steady for each experiment but differs considerably between the two. For Experiment 2, the average value for this sum was $8.6 \mu$ mole $\mathrm{g}^{-1}$ wet weight, with small variability between the six chickens $(3.5 \%)$, which is only $60 \%$ of that detected in Experiment $1\left(14.3 \mu\right.$ mole $\mathrm{g}^{-1}$, Coefficient of Variation $\left.=14 \%\right)$. Elucidation of whether this difference is due to a change in commercial practice (e.g. genotype, production or processing) between the two experiments would require further study.

\subsection{Glucose, glucose phosphate and $\mathrm{pH}$.}

The analytical method used for the quantification of sugar phosphates, involving the use of alkaline phosphatase (EC 3.1.3.1) to break them down to the parent sugars for analysis by HPLC, 
precluded the identification of individual isomers of sugar phosphates. Identification of the glucose phosphate as glucose-6-phosphate was confirmed by GC-MS.

Glucose and glucose-6-phosphate were present at an early stage post-slaughter and remained at similar concentrations throughout processing (Experiment 1, Table 1). After chilling (Experiment 2, Table 2), although the concentration of glucose initially remains similar, declining after 55 hours, the concentration of glucose-6-phosphate decreases substantially. In both cases, these changes represent significant linear $(\mathrm{P}<0.001)$ and quadratic $(\mathrm{P}<0.05)$ relationships. These experiments were designed to follow the detailed breakdown of ATP metabolites and the formation of flavour precursors in a small number of chickens, rather than to sample the retail chicken population as a whole. Few other studies have reported the effect of time post-slaughter on glucose and glucose-6-phosphate concentrations in poultry post-slaughter; van Hoof (1979) showed a rise or fall in glucose, depending on pre-slaughter handling. The results in Table 1 and 2 agree with those reported for glucose-6phosphate in beef (Koutsidis, et al., 2008), for which a slight fall was observed, but disagree with those for glucose in beef which show a steady increase post-slaughter. Unlike in beef, measurable quantities of mannose, fructose or their phosphates were not detected.

In Experiment 2 there was considerable variation in $\mathrm{pH}$ between individual chickens at each time point sampled, generally ranging from around 6.0 to 6.4 (Table 2). Plotting glucose and glucose-6phosphate concentration against the $\mathrm{pHu}$ of the breast meat shows that these sugars are higher at decreased $\mathrm{pHu}$ values at most time points (Table 3). This trend is illustrated in Figure 3 for $4 \mathrm{~h}$ and 200h post-slaughter. A similar trend was observed at all times of chilled storage, albeit not significantly $(\mathrm{P}<0.10)$ at $150 \mathrm{~h}$ post-slaughter, and also for these sugars individually and summed (Table 3). While such simple correlations must be treated with caution, and the number of birds does not justify more rigorous statistical analysis, there does appear to be a consistent trend. A similar effect has been observed elsewhere with more than 100 chickens (Farmer et al., unpublished data). This finding is also consistent with the work reported by Immonen and Puolanne (2000) who showed a non-linear relationship between $\mathrm{pHu}$ and residual carbohydrate (glycogen + glucose $)$ in beef. Under post-mortem anaerobic conditions in meat, the glycolysis pathway converts glucose and 
glucose-6-phosphate to lactic acid to give decreased $\mathrm{pH}$. In other species' meats, a high pHu can be caused by an insufficient supply of glycogen for this reaction to go to completion, perhaps due to stress prior to slaughter. The high $\mathrm{pHu}$ in Experiment 2 indicates that there has been considerable glycogen depletion prior to slaughter, thus limiting $\mathrm{pH}$ decline. Muscle glucose and glucose-6phosphate reflects the balance between production from glycogen post-mortem and conversion to lactate as glycolysis proceeds, and also any influences of stress on carbohydrate mobilization preslaughter. Van Hoof et al. (1979) noted lower levels of glucose in turkey breast muscle in those birds that were held at the slaughter plant for $24 \mathrm{~h}$ after arrival than in those birds slaughtered without transportation. The $\mathrm{pHu}$ reported by van Hoof et al. (1979) ranges from around 6.1 to 6.4, and over this range there was an indication of an inverse relationship between glucose and $\mathrm{pHu}$, similar to that reported in Experiment 2 (Figure 3). Campbell (1984) also noted an inverse relationship between $\mathrm{pHu}$ and glucose + glucose-6-phosphate in porcine longissimus dorsi muscle with a normal pHu (5.6). Daly et al. (1999) observed lower residual glucose in bovine longissimus thoracicus that had lower glycogen levels at slaughter in animals of normal pHu (5.6-5.7) and proposed that this relationship is caused by the activity of the debranching enzyme $(\alpha-1,6-$ glucosidase).

\section{[Table 3]}

\section{[Figure 3]}

The average $\mathrm{pH}$ at $28 \mathrm{~h}$ was $6.30(\mathrm{SD}=0.13)($ Table 2$)$; the $\mathrm{pH}$ always exceeded 6.0 and for some chickens was as high as 6.4. These values are higher than those (average $\mathrm{pHu} 6.03$ ) reported for breast muscle by Yla-Ajos et al. (2007), and also higher than those in most of the reports detailed in the same study, which reported $\mathrm{pHu}$ ranges from 5.6-5.8 up to 6.1-6.2. The $\mathrm{pH}$ of the breast muscle (Table 2) did not show a consistent fall with time post-mortem, in contrast with the results of Tomaszewska-Gras et al. (2011) who reported a fall in $\mathrm{pH}$ from 6.3 at to 5.4 by $24 \mathrm{~h}$ post-slaughter, rising again slightly after $72 \mathrm{~h}$ post-slaughter. Berge et al., (1997) showed that the $\mathrm{pHu}$ of emu meat was ca. 6.0 in birds that experienced 10 hours transport without food immediately prior to slaughter but 5.5 in unstressed birds. This relatively high $\mathrm{pH}$ and absence of $\mathrm{pH}$ fall observed (Table 2) is also 
consistent with a low glycolytic potential and the occurrence of stress pre-slaughter. The effect of this on the eating quality of the meat would justify further study.

\subsection{ATP, ADP, AMP.}

ATP was present during the early post-slaughter period (Table 1), but its concentration showed a non-significant downward trend with time, dropping from $2.4 \mu$ mole $\mathrm{g}^{-1}$ wet weight $\left(1.3 \mathrm{mg} \mathrm{g}^{-1}\right)$ at ca. 15 minutes post-slaughter to $1.3 \mu$ mole $\mathrm{g}^{-1}$ at ca 123 minutes post-slaughter. Changes in ADP and AMP during these early stages post-slaughter were not statistically significant, probably due to the fact that the differences due to time post-slaughter were not great compared with the considerable natural variation between individual chickens, with ATP concentrations at ca. 15 minutes ranging from 0.9 to $4.5 \mu$ mole $^{-1}$, and the fact that separate groups of six chickens were taken for analysis at the three time points. De Fremery (1960) reported the "initial" ATP content of chicken muscle to be $4.8 \mathrm{mg} \mathrm{g}^{-1}$ fresh tissue $\left(9.5 \mu\right.$ moles $\left.\mathrm{g}^{-1}\right)$, while Santé et al. (2000) reports falling concentrations of 5-6 $\mu$ moles $\mathrm{g}^{-1}$ in turkey muscle at 3 and 20- mins post-slaughter, with lower ATP levels in birds stunned at $600 \mathrm{~Hz}$ compared to 50Hz. The ATP levels reported (Sante, et al., 2000) are approximately 3-5 times higher than the values we obtained at ca. 15 minutes post-slaughter (Table 1).

In Experiment 2, one set of six chickens were followed throughout the chill period. At 4 hours post-slaughter (Table 2), AMP was predominant amongst the adenosine nucleotides, with $0.8 \mu$ mole $\mathrm{g}^{-1}$ compared to $0.3 \mu$ mole $^{-1}$ for both ATP and ADP. During chilled storage from 4 to 200 hours, the concentrations of all three compounds decreased further. The significance of the quadratic relationship reflected the fact that the concentrations of all three compounds decreased initially and then became steady after 55 or 100 hours. The low concentration of ATP is in accord with the expected disappearance of ATP at onset of rigor mortis, occurring at ca. 6 hours post-mortem in chilled chicken muscle (Schreurs, 2000). Observation of the data for individual chickens (not shown) shows considerable variation for ATP but good agreement for ADP and AMP.

\subsection{Inosine 5'-monophosphate (IMP), inosine and hypoxanthine.}

IMP was the most abundant ATP breakdown product in both Experiments, up until 100h postslaughter, when inosine became more abundant (Figure 4). This agrees with the findings of Lee and 
Newbold (1963), who also reported that IMP is the predominant nucleotide of muscle in rigor mortis at one day post-slaughter. A considerable amount of IMP $\left(7.8 \mu\right.$ mole $\mathrm{g}^{-1}$ wet weight $)$ was present after only 10 mins post-slaughter (Table 1), indicating a high activity at this early stage postslaughter for the deamination of AMP by 'adenylate aminohydrolase' (EC 3.5.4.6), relative to IMP breakdown. This compares with less than $2 \mu$ mole $\mathrm{g}^{-1}$ reported in turkey muscle at 2 and 20 mins post-slaughter (Sante, et al., 2000). The levels of ATP and IMP in the current study are similar to those reported by van Hoof (1979) for birds manually slaughtered. The concentrations of inosine at $4 \mathrm{~h}$ in Experiment 2 (Table 2) are slightly higher than in turkey breast muscle manually slaughtered (van Hoof, 1979), while the levels of hypoxanthine at $4 \mathrm{~h}$ are approximately a factor of $3 \mathrm{x}$ lower than those quoted by the same author for turkey breast muscle. These differences between our study and published literature on turkey breast muscle may reflect species differences and/or the effect of stress both pre-slaughter and at slaughter on the rate of post-mortem glycolysis.

\section{[Figure 4]}

The low concentrations for ATP and high levels of IMP at 10 mins post-slaughter, reported in Table 1, suggest an accelerated rate of post-mortem metabolism. This is supported by the results of Santé et al. (2000) which, although on turkeys rather than chickens, showed that a lower ratio of ATP to IMP was associated with a faster rate of post-mortem glycolysis (as evidenced by $\mathrm{pH}$ decline), arising from a high frequency stunning regime. The low ATP/IMP ratios coupled with the lower ATP levels in both Experiments 1 and 2 (Tables 1 and 2), compared to data for similar time points reported by Santé et al. (2000), indicate that post-mortem glycolysis was extremely rapid in the current studies. These results therefore indicate that the birds used in the current study underwent a very rapid post-mortem glycolysis that may have resulted from a combination of stress at slaughter and stunning systems that induced wing flapping at slaughter. In addition, the high $\mathrm{pHu}$ values, particularly in Experiment 2, indicate considerable pre-slaughter stress resulting in depletion of carbohydrate stores pre-slaughter. The first of these studies was conducted in summer while the second was in winter; however, in Northern Ireland inclement weather conditions during transport could contribute to pre-slaughter stress at any season. 
The chickens used for Experiment 2 had lower concentrations of IMP than Experiment 1, in line with the $60 \%$ lower concentration of total nucleotides and related compounds. During chilled storage at $4^{\circ} \mathrm{C}$, IMP concentration fell from 5.3 to $2.7 \mu$ mole $\mathrm{g}^{-1}$ wet weight between 4 and $150 \mathrm{~h}$ post-slaughter. Terasaki et al. (1965) reported similar concentrations of IMP (210-270 mg $100 \mathrm{~g}^{-1}$ wet weight $=5.4-6.9 \mu$ mole $\left.\mathrm{g}^{-1}\right)$ at 8 hours post-mortem, using a similar extraction method with ion exchange chromatography. Their data also showed a decrease in concentration to half the initial value after 4-6 days.

The presence of inosine, even at 10 minutes post-slaughter (Table 1), indicated that the breakdown of IMP into inosine and phosphate commenced at an early stage. Statistical analysis did not show any significant differences for inosine at 10, 20 and 115 minutes post-slaughter. However, during extended chilled storage (Table 2), inosine increased with time. These results agree with those reported by Terasaki et al. (1965) who found similar concentrations of inosine in chicken breast meat held at $4{ }^{\circ} \mathrm{C}$ : $1 \mu$ mole $\mathrm{g}^{-1}$ wet weight after 24 hours increasing to $4 \mu$ mole $\mathrm{g}^{-1}$ after 48 hours.

Hypoxanthine was present at low concentrations at early stages post-slaughter (Table 1) but increased steadily and linearly throughout post-slaughter chilled storage (Table 2) from 0.1 to 2.3 $\mu$ moles $\mathrm{g}^{-1}$ at $200 \mathrm{~h}$ post-slaughter (Figures 4(a), 5). These results are in agreement with those reported by other researchers. Davidek et al. (1967) reported the presence of hypoxanthine only in poultry meat aged for more than 41 hours. However, its apparent absence at earlier stages was probably due to the higher detection thresholds arising from the use of paper chromatography. Park et al., (1982) have determined hypoxanthine in chicken samples immediately after their purchase from a local market and after 7 days storage at $4{ }^{\circ} \mathrm{C}$. They reported $0.9 \pm 0.2 \mu$ moles $\mathrm{g}^{-1}$ for hypoxanthine in control and $2.1 \pm 0.8$ after 7 days storage ( $>150$ hours post-slaughter).

\section{[Figure 5]}

A plot of the formation and decline of base-containing metabolites (Figure 4) shows that, the rate of decline of IMP is steady to 150 hours and that the rate of formation of hypoxanthine is steady throughout. Inosine, in contrast, shows a non-linear relationship with time, consistent with the 
balance between formation and breakdown pathways shifting towards the latter with time. These relationships were also observed for the individual chickens (not shown).

\subsection{Ribose and ribose-5-phosphate.}

As for glucose-6-phosphate, the enzymatic quantitative method employed here did not distinguish between different phosphate forms of ribose. The use of GC-MS confirmed that the ribose phosphate detected was ribose-5-phosphate and also identified ribulose, ribulose 5-phosphate, xylulose and xylulose 5-phosphate in trace amounts.

Ribose was present at very low concentrations at early stages post-slaughter (Experiment 1, Table 1) with formation commencing between 33 and 123 minutes post-mortem. In Experiment 2, ribose increased markedly and linearly with time during chilled storage up to 200 hours post-slaughter (Table 2), with a 20-fold increase between 4 and 200 hours. In contrast, ribose phosphate was present at low concentrations in most chickens during the early stages post-slaughter. It peaked at 28 - 55 hours and then decreased during chilled storage.

It is necessary to consider whether, after 8 days refrigerated storage, microbial activity may have been the cause of a loss of ribose and ribose phosphate. However, if such an effect were dominant, an exponential growth in microflora would be expected to give a concomitant change in these compounds and other sugars and this was not observed. Nor was there any evidence of spoilage in terms of odour or appearance.

As ribose has proved to be an important limiting factor for the formation of chicken flavor (Aliani \& Farmer, 2005b), it was of particular interest to trace its formation in chicken meat and its evolution with time throughout the post-slaughter and chilled storage period. While previous authors have followed these pathways via the formation of hypoxanthine (Lee \& Newbold, 1963), none have determined ribose and ribose phosphate.

One major source of ribose in chicken is believed to be inosine monophosphate (IMP) originating from ATP (D.S. Mottram \& Madruga, 1994). Figure 6 shows the possible degradation of IMP by three different pathways as proposed by Lee and Newbold (1963). They suggest that IMP may be dephosphorylated to give inosine (pathway i), which itself might break down to ribose and 
hypoxanthine (ii) or ribose-1-phosphate and hypoxanthine (iii) or IMP might be degraded directly to ribose-5-phosphate and hypoxanthine (iv). The evidence presented in Tables 1 and 2 is only partly consistent with this model. IMP decreases, inosine remains roughly steady and ribose and hypoxanthine accumulate, as predicted (Lee \& Newbold, 1963). However, it is evident from Table 2 and Figure 5 that the accumulation of hypoxanthine is greater and more rapid than that of ribose. This suggests either that hypoxanthine is also formed by a different pathway to route (ii) or that ribose breaks down further. The likely pathways for forming hypoxanthine would be routes (iii) and (iv) which should also give ribose-1-phosphate or ribose-5-phosphate (Figure 6), both of which would be measured as ribose phosphate in this study. Table 2 and Figure 5 show that ribose phosphate is present at greater quantities than hypoxanthine at $4 \mathrm{~h}$ and $28 \mathrm{~h}$ post-slaughter but declines later during chilled storage. These elevated early levels of ribose phosphate suggest that there is an additional route of formation of ribose phosphate at early times post-slaughter not explained by the Lee and Newbold model (Figure 6). Koutsidis et al. (2008) suggest that ribose-5phosphate is dephosphorylated to release ribose and this may explain part but not all of the decline and rise in these compounds. Thus, these results suggest that while both ribose and ribose phosphate are probably formed by the breakdown of IMP, both compounds react further. This is further supported by the gradual loss of total ribose-containing metabolites over time in chilled storage from 9.0 to $7.2 \mu$ mole $\mathrm{g}^{-1}$ wet weight from 4 to 200 hours post-slaughter, while total nucleotides remains stable (Table 2, Figure 4(a, b)). It is possible that these additional reactions of formation and breakdown of sugars may be related to the pentose phosphate pathway or reactions with protein and this is the subject of further research. A detailed kinetic study with more sampling times would further elucidate the relationships between these post-slaughter metabolic pathways.

\section{[Figure 6]}

These results demonstrate that large quantities of IMP and inosine present in chicken postslaughter were not converted into ribose (Tables 1,2, Figure 4(b)). A maximum of 5-6\% of the potential ribose was present as ribose (at 200 hours) or ribose phosphate (28 hours). Chicken meat is usually purchased and consumed between 28 and 100 hours post-slaughter and, at this time, the 
potential ribose is largely present as IMP. To optimise the release of ribose from this pathway, and make it available as a precursor of flavour formation, it will be necessary to better understand the enzymatic systems governing the breakdown of IMP and inosine. Further research on this subject will be reported separately.

\section{Acknowledgement}

We gratefully acknowledge funding and support from the Department of Education and Learning and from local industry in Northern Ireland.

\section{References}

Aliani, M., \& Farmer, L. J. (2005a). Precursors of chicken flavor. I. Determination of some flavor precursors in chicken muscle. Journal of Agricultural and Food Chemistry, 53 (15), 60676072 .

Aliani, M., \& Farmer, L. J. (2005b). Precursors of chicken flavor. II. Identification of key flavor precursors using sensory methods. Journal of Agricultural and Food Chemistry, 53(16), $6455-6462$.

Berge, P., Lepetit, J., Renerre, M., \& Touraille, C. (1997). Meat quality traits in the emu (Dromaius novaehollandiae) as affected by muscle type and animal age. Meat Science, 45(2), 209-221.

Bodwell, C. E., Pearson, A. M., \& Spooner, M. E. (1965). Post-Mortem Changes in Muscle. I. Chemical Changes in Beef. Journal of Food Science, 766-772.

Campbell, W. S. (1984). Preslaughter treatment of meat animals: meat quality and physiological correlates. Unpublished PhD, Queen's University of Belfast.

Daly, C. C., Young, O. A., Graafhuis, A. E., Moorhead, S. M., \& Easton, H. S. (1999). Some effects of diet on beef meat and fat attributes. New Zealand Journal of Agricultural Research, 42(3), 279-287.

Dannert, R. D., \& Pearson, A. M. (1967). Concentration of inosine 5'-monophosphate in meat. Journal of Food Science, 32(1), 49-57.

Davidek, J., \& Khan, A. W. (1967). Estimation of inosinic acid in chicken muscle and its formation and degradation during post-mortem aging. Journal of Food Science, 32, 155-157.

De Fremery, D. (1966). Some aspects of postmortem changes in poultry muscle. In E. J. Briskey, R. G. Cassens \& J. C. Trautman (Eds.), The physiology and biochemistry of muscle as a food (pp. 429). London: The University of Wisconsin press.

De Fremery, D., \& Pool, M. F. (1960). Biochemistry of chicken muscle as related to rigor mortis and tenderization. Food Research, 25, 73-87.

Farmer, L. J., Hagan, T. D. J., \& Paraskevas, O. (1996). A comparison of three sugars and inosine monophosphate as precursors of meat aroma. In A. J. Taylor \& D. S. Mottram (Eds.), Flavour Science: Recent Developments (pp. 225-230). Cambridge. 
Farmer, L. J., Hagan, T. D. J., \& Paraskevas, O. (1998). Role of selected precursors in meat flavour formation. In Y. L. Xiong, C.-T. Ho \& F. Shahidi (Eds.), Quality Attributes of Muscle Foods (pp. 159-172). New York: Plenum Publ. Corp.

Farmer, L. J., Kennedy, J. T., \& Hagan, T. D. J. (2009). Contribution of aqueous precursors to the odour and flavour of cooked meats. In $55^{\text {th }}$ International Congress of Meat Science and Technology. Copenhagen.

Greaser, M. L. (1986). Conversion of muscle to meat. In P. J. Bechtel (Ed.), Muscle as food (pp. $37-$ 102). Orlando, Florida: Academic Press.

Immonen, K., \& Puolanne, E. (2000). Variation of residual glycogen-glucose concentration at ultimate $\mathrm{pH}$ values below 5.75. Meat Science, 55(3), 279-283.

Koutsidis, G., Elmore, J. S., Oruna-Concha, M. J., Campo, M. M., Wood, J. D., \& Mottram, D. S. (2008). Water-soluble precursors of beef flavour. Part II: Effect of post-mortem conditioning. Meat Science, 79, 270-277.

Leblanc, D. J., \& Ball, A. J. S. (1977). A fast one-step method for the silylation of sugars and sugar phosphates. Analytical Biochemistry, 84, 574-578.

Lee, C. A., \& Newbold, R. P. (1963). The pathway of degradation of inosinic acid in bovine skeletal muscle. Biochimica et Biphysica Acta., 72, 349-352.

Lilyblade, A. L., \& Peterson, D. W. (1962). Inositol and free sugars in chicken muscle post-mortem. Journal of Food Science, 27, 245-249.

Mottram, D. S. (1994). Flavour compounds formed during the Maillard reaction. In T. H. Parliment, M. J. Morello \& R. J. McGorrin (Eds.), Thermally Generated Flavors. Maillard, Microwave, and Extrusion Processes (pp. 104-126). Washington DC: American Chemical Society.

Mottram, D. S. (1998). Flavour formation in meat and meat products: a review. Food Chemistry, $62(4), 415-424$.

Mottram, D. S., \& Madruga, M. S. (1994). The role of inosine monophosphate as a precursor in meat aroma. In H. Maarse \& D. G. van der Heij (Eds.), Trends in Flavour Research (pp. 339-344). Amsterdam: Elsevier.

Parrish, F. C., Goll, D. E., Newcomb II, W. J., Lumen, B. O., Chaudhry, H. M., \& Kline, E. A. (1969). Molecular properties of post-mortem muscle. 7. Changes in nonprotein nitrogen and free amino acids of bovine muscle. Journal of Food Science, 34, 196-202.

Pearson, A. M. (1987). Muscle function and postmortem changes. In J. F. Price \& B. S. Schweigert (Eds.), The science of meat and meat products (pp. 151-191). Westport, Connecticut: Food and Nutrition Press.

Sante, V., Le Pottier, G., Astruc, T., Mouchoniere, M., \& Fernandez, X. (2000). Effect of stunning current frequency on carcass downgrading and meat quality of turkey. Poultry Science, 79(8), 1208-1214.

Schreurs, F. J. G. (2000). Post-mortem changes in chicken muscle. World's Poultry Science Journal, $56,321-346$.

Terasaki, M., Kajikawa, M., Fujita, E., \& Ishi, K. (1965). Studies on the flavor of meats, Part I. Formation and degradation of inosinic acids in meats. Agricultural and Biological Chemistry, 29(3), 208-215.

Tomaszewska-Gras, J., Schreurs, F. J. G., Kijowski, J. (2011). Post mortem development of meat quality as related to changes in cytoskeletal proteins of chicken muscles. British Poultry Science, 52(2), 189-201.

van Hoof, J. (1979). Influence of ante- and peri-mortem factors on biochemical and physical characteristics of turkey breast muscle. Tijdschrift voor diergeneeskunde, 104(2), 29-36. 
Vernin, G., \& Parkanyi, C. (1982). Mechanisms of formation of heterocyclic compounds in Maillard and pyrolysis reactions. In G. Vernin (Ed.), Chemistry of Heterocyclic Compounds in Flavors and Aromas (pp. 151-207.). Chichester: Ellis Horwood.

Yla-Ajos, M., Ruusunen, M. and Puolanne. E. (2007). Glycogen debranching enzyme and some other factors relating to postmortem $\mathrm{pH}$ decrease in poultry muscles. Journal of the Science of Food and Agriculture 87:394-398. 
Table 1: Effect of time post-slaughter on the concentration of ribonucleotides and sugars ( $\mu$ mole $\mathrm{g}^{-1}$ wet weight) in breast meat from six chickens (Experiment 1)

\begin{tabular}{|c|c|c|c|c|c|c|}
\hline \multirow[b]{2}{*}{ Metabolite $^{\mathrm{a}}$} & \multicolumn{3}{|c|}{ Time post-slaughter } & \multicolumn{3}{|c|}{ ANOVA } \\
\hline & Stage $\mathbf{A}^{\mathbf{b}}$ & Stage B & Stage C & SEM & $\begin{array}{c}\text { Sig } \\
\text { Time_h }\end{array}$ & $\begin{array}{l}\text { Sig } \\
\text { Lin }\end{array}$ \\
\hline ATP & 2.42 & 1.78 & 1.33 & 0.394 & NS & NS \\
\hline ADP & 1.01 & 0.67 & 0.80 & 0.167 & NS & NS \\
\hline AMP & 0.98 & 0.58 & 0.83 & 0.258 & NS & NS \\
\hline IMP & 7.78 & 9.52 & 8.29 & 0.788 & NS & NS \\
\hline Inosine & 2.30 & 2.52 & 1.55 & 0.385 & NS & NS \\
\hline Hypoxanthine & 0.14 & 0.10 & 0.29 & 0.055 & NS & $\mathrm{P}<0.05$ \\
\hline Ribose & 0.01 & $\mathrm{nd}^{\mathrm{c}}$ & 0.14 & 0.007 & $\mathrm{P}<0.001$ & $\mathrm{P}<0.001$ \\
\hline Ribose phosphate & 0.07 & 0.04 & 0.09 & 0.015 & NS & NS \\
\hline Glucose & 1.05 & 1.94 & 1.93 & 0.392 & NS & NS \\
\hline Glucose phosphate & 0.35 & 0.36 & 0.33 & 0.130 & NS & NS \\
\hline $\begin{array}{l}\text { Total ribose-containing } \\
\text { metabolites }^{\mathrm{d}}\end{array}$ & 14.6 & 15.1 & 13.0 & 0.762 & NS & NS \\
\hline $\begin{array}{l}\text { Total base-containing } \\
\text { metabolites }\end{array}$ & 14.6 & 15.2 & 13.1 & 0.754 & NS & NS \\
\hline
\end{tabular}

a: ATP: adenosine triphosphate; ADP: adenosine diphosphate; AMP: adenosine monophosphate; IMP: inosine monophosphate

b: Stage A, B and C of processing as illustrated in Figure 1

c: nd $=$ not detected at $0.012 \mu \mathrm{g}$ or 0.08 nmoles in $20 \mu \mathrm{L}$ injection, which corresponds to $0.01 \mu$ moles $\mathrm{g}^{-1}$ wet weight raw chicken meat; statistical significance is the same whether conducted using zero or $0.01 \mu$ moles $\mathrm{g}^{-1}$ for this value. If this value is omitted, the difference between ribose concentrations at Stage $\mathrm{A}$ and $\mathrm{C}$ remains significant $(\mathrm{P}<0.001)$.

$\mathrm{d}$ : Total ribose ( $\mu$ mole $\mathrm{g}^{-1}$ wet weight) included in ATP, ADP, AMP, IMP, inosine, ribose and ribose phosphate 
e: Total nucleotides and related compounds $\left(\mu\right.$ mole $^{-1}$ wet weight $)=$ ATP, ADP, AMP, IMP, inosine and Hx 
Table 2: Effect of time of chilled storage on concentrations of ribonucleotides and sugars ( $\mu$ mole $\mathrm{g}^{-1}$ wet weight) in breast muscle from six chickens (Experiment 2)

\section{Time chilled storage post-slaughter (hours)}

\section{ANOVA}

\begin{tabular}{|c|c|c|c|c|c|c|c|c|c|c|}
\hline Metabolite $^{\mathrm{a}}$ & 4 & 28 & 55 & 100 & 150 & 200 & SEM $^{\mathbf{b}}$ & $\begin{array}{c}\text { Sig } \\
\text { Time_h }\end{array}$ & $\begin{array}{l}\text { Sig } \\
\text { Lin }\end{array}$ & $\begin{array}{c}\text { Sig } \\
\text { Quad }\end{array}$ \\
\hline ATP & 0.27 & 0.29 & 0.15 & 0.15 & 0.10 & 0.12 & 0.022 & $\mathrm{P}<0.001$ & $\mathrm{P}<0.001$ & $\mathrm{P}<0.01$ \\
\hline ADP & 0.29 & 0.20 & 0.17 & 0.17 & 0.16 & 0.16 & 0.005 & $\mathrm{P}<0.001$ & $\mathrm{P}<0.001$ & $\mathrm{P}<0.001$ \\
\hline AMP & 0.78 & 0.28 & 0.33 & 0.27 & 0.29 & 0.30 & 0.019 & $\mathrm{P}<0.001$ & $\mathrm{P}<0.001$ & $\mathrm{P}<0.001$ \\
\hline IMP & 5.31 & 4.88 & 4.21 & 3.49 & 2.82 & 2.72 & 0.120 & $\mathrm{P}<0.001$ & $\mathrm{P}<0.001$ & $\mathrm{P}<0.001$ \\
\hline Inosine & 2.03 & 2.35 & 2.79 & 216 & 3.21 & 3.29 & 0.121 & $\mathrm{P}<0.001$ & $\mathrm{P}<0.001$ & $\mathrm{P}<0.001$ \\
\hline Hypoxanthine & 0.14 & 0.40 & 0.75 & 1.26 & 1.76 & 2.27 & 0.093 & $\mathrm{P}<0.001$ & $\mathrm{P}<0.001$ & NS \\
\hline Ribose & 0.02 & 0.09 & 0.18 & 0.28 & 0.34 & 0.38 & 0.016 & $\mathrm{P}<0.001$ & $\mathrm{P}<0.001$ & $\mathrm{P}<0.001$ \\
\hline Ribose phosphate ${ }^{c}$ & 0.32 & 0.44 & 0.37 & 0.30 & 0.26 & 0.28 & 0.028 & $\mathrm{P}<0.001$ & $\mathrm{P}<0.001$ & NS \\
\hline Glucose & 0.83 & 0.97 & 1.04 & 0.87 & 0.73 & 0.61 & 0.064 & $\mathrm{P}<0.01$ & $\mathrm{P}<0.001$ & $\mathrm{P}<0.05$ \\
\hline Glucose phosphate $^{\mathrm{c}}$ & 0.73 & 0.61 & 0.52 & 0.39 & 0.22 & 0.39 & 0.072 & $\mathrm{P}<0.001$ & $\mathrm{P}<0.001$ & $\mathrm{P}<0.05$ \\
\hline $\mathrm{pH}$ & 6.19 & 6.30 & 6.25 & 6.28 & 6.28 & 6.33 & 0.024 & $\mathrm{P}<0.05$ & $\mathrm{P}<0.01$ & NS \\
\hline $\begin{array}{l}\text { Total ribose- } \\
\text { containing } \\
\text { metabolites }^{d}\end{array}$ & 9.03 & 8.53 & 8.19 & 7.82 & 7.17 & 7.25 & 0.159 & $\mathrm{P}<0.001$ & $\mathrm{P}<0.001$ & $\mathrm{P}<0.05$ \\
\hline $\begin{array}{l}\text { Total base- } \\
\text { containing } \\
\text { metabolites }\end{array}$ & 8.84 & 8.40 & 8.39 & 8.50 & 8.33 & 8.86 & 0.138 & $\mathrm{P}<0.05$ & NS & $\mathrm{P}<0.01$ \\
\hline
\end{tabular}


a: ATP: adenosine 5'-triphosphate; ADP: adenosine 5'-diphosphate; AMP: adenosine 5'-monophosphate; IMP: inosine 5'-monophosphate

b: SEM: Standard error of means

c: Ribose and glucose phosphates here include all phosphates, though additional analyses showed that glucose-6-phosphate and ribose-5-phosphate were the by far the most abundant isomers

d: Total ribose ( $\mu$ mole $\mathrm{g}^{-1}$ wet weight) included in ATP, ADP, AMP, IMP, inosine, ribose and ribose phosphate

e: Total nucleotides and related compounds $\left(\mu\right.$ mole $\mathrm{g}^{-1}$ wet weight $)=$ ATP, ADP, AMP, IMP, inosine and Hx 
Table 3. Pearson's correlation between glucose and glucose-6-phosphate concentrations and pHu, at different times during chilled storage (Experiment 2)

\begin{tabular}{ccccccc}
\hline $\begin{array}{c}\text { Time post- } \\
\text { slaughter }\end{array}$ & GLU & GLU & GP & GP & GLU+GP & GLU*GP \\
\hline & $\mathrm{R}$ & $\mathrm{Sig}^{\$}$ & $\mathrm{R}$ & $\mathrm{Sig}$ & $\mathrm{R}$ & $\mathrm{Sig}$ \\
$4 \mathrm{~h}$ & -0.957 & $* *$ & -0.908 & $*$ & -0.936 & $* *$ \\
$28 \mathrm{~h}$ & -0.850 & $*$ & -0.917 & $* *$ & -0.894 & $*$ \\
$55 \mathrm{~h}$ & -0.812 & $*$ & -0.835 & $*$ & -0.838 & $*$ \\
$100 \mathrm{~h}$ & -0.862 & $*$ & -0.836 & $*$ & -0.850 & $*$ \\
$150 \mathrm{~h}$ & -0.778 & $\mathrm{NS}{ }^{\#}$ & -0.730 & $\mathrm{~ns}^{\#}$ & -0.764 & $\mathrm{~ns}$ \\
$200 \mathrm{~h}$ & -0.916 & $*$ & -0.945 & $* *$ & -0.930 & $* *$ \\
\hline
\end{tabular}

$\$$ From table of critical values for Pearson's product moment correlation coefficients, two tailed test, $\mathrm{df}=4 ; *, * *=\mathrm{P}<0.05, \mathrm{P}<0.01$

\# NS, not significant, $\mathrm{P}>0.05<0.10$ 


\section{List of figures.}

Figure 1 Summary of poultry slaughtering and processing line showing sampling times for Experiment 1.

Figure 2. Diagram showing sampling pattern for chicken breast meat samples. Samples (ca 3g) were taken from areas A to L from six chickens according to a random sampling pattern, without using cut surfaces left by a previous sample.

Figure 3. Effect of pHu on glucose (GLU) and glucose-6-phosphate (G6P) concentration at (a) 4h and (b) $200 \mathrm{~h}$.

Figure 4. Effect of time of chilled storage (4 to 200 hours post-slaughter) on the concentrations of metabolites in Experiment 2: (a) base-containing metabolites and (b) ribose containing metabolites. TBCM, TRCM = total base-containing and ribose-containing metabolites, respectively.

Figure 5. Changes in concentrations of hypoxanthine (Hx), ribose and ribose-5-phosphate (RP) during chilled storage (Experiment 2).

Figure 6: The possible degradation of IMP by different pathways in bovine skeletal muscle from Lee and Newbold (1963). 
Figure 1

Figure

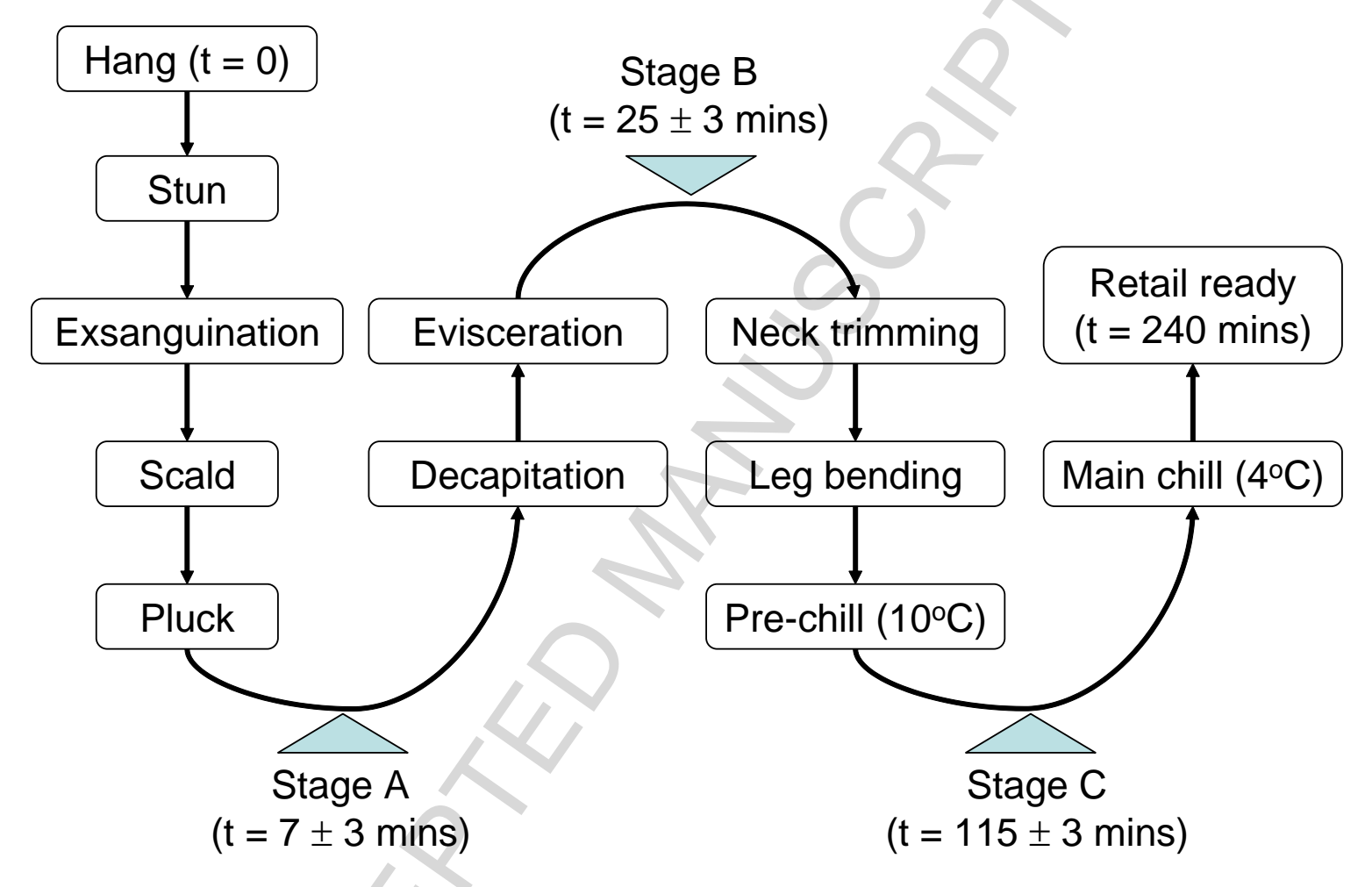


Figure 2.

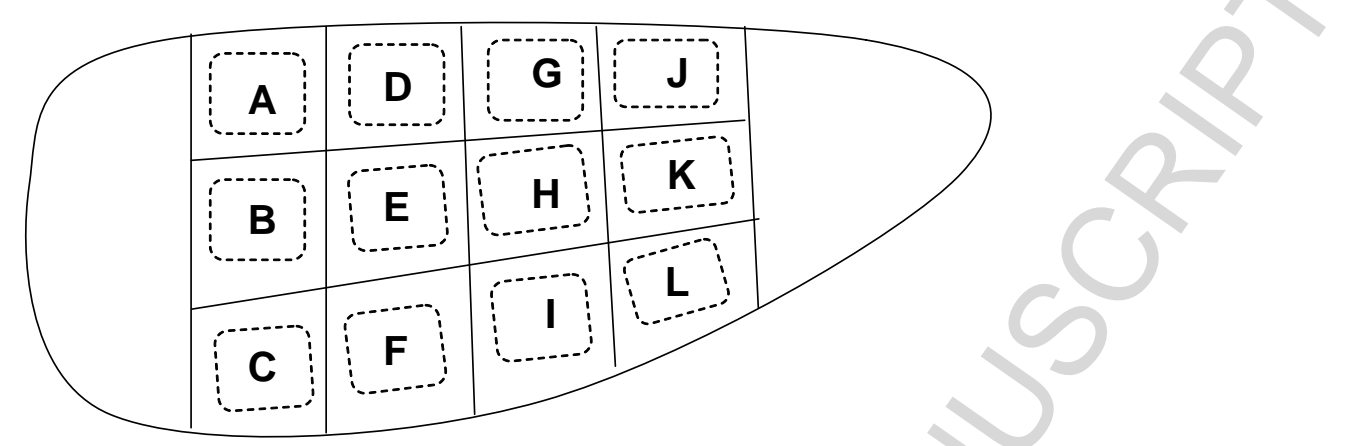


Figure 3.

ACGEPTED MANUSCRIPT
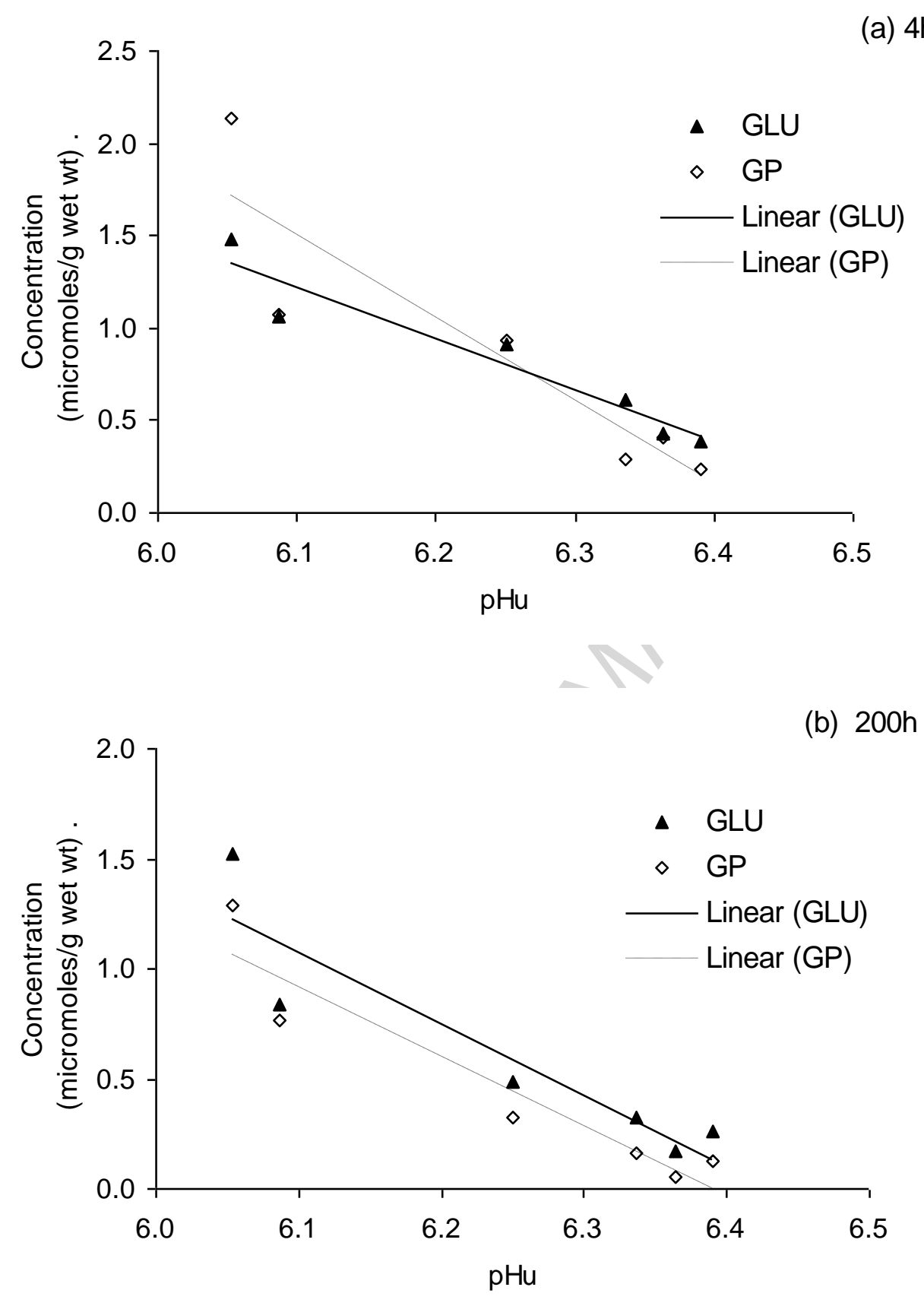
Figure 4.
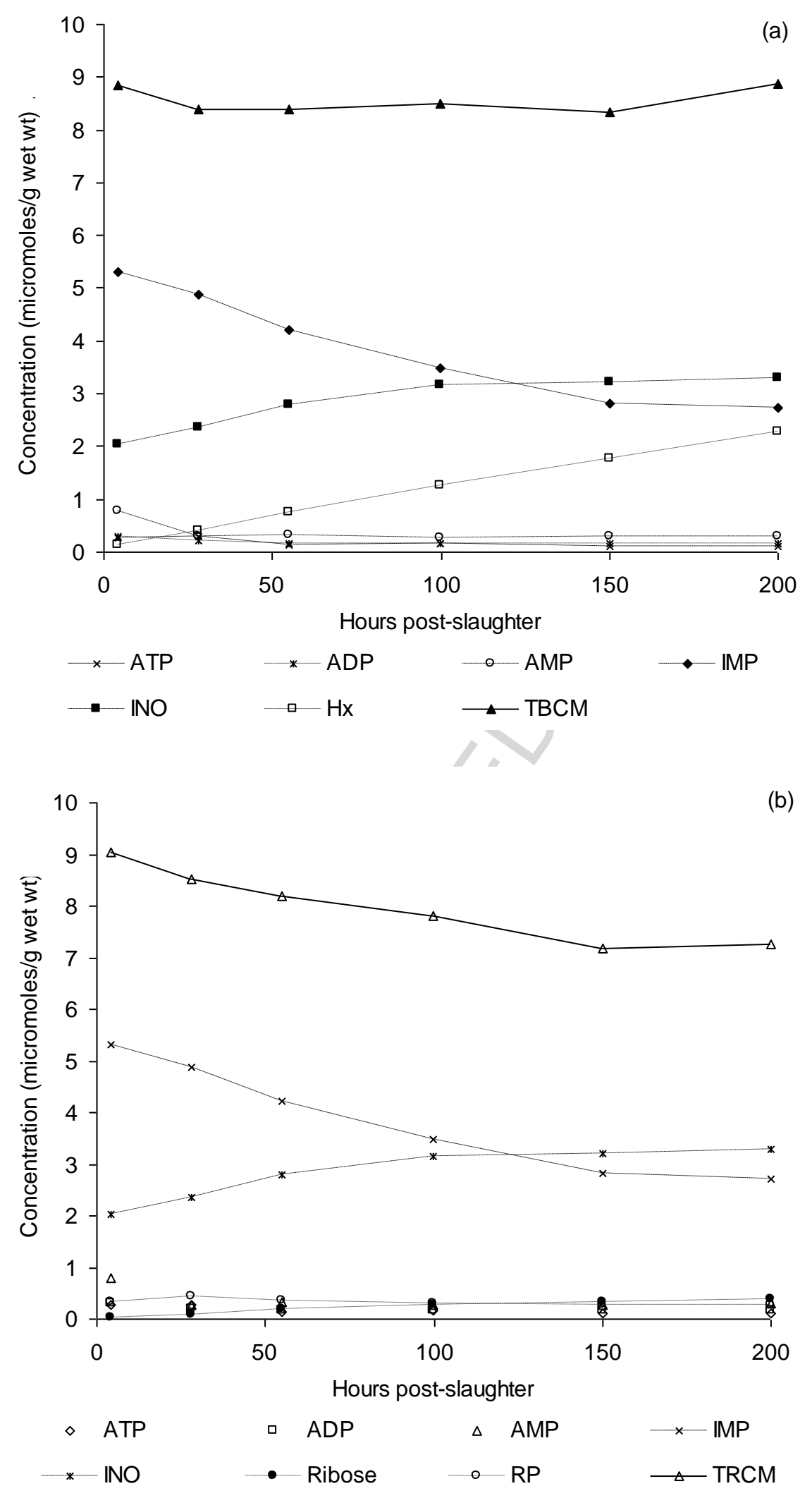
Figure 5.

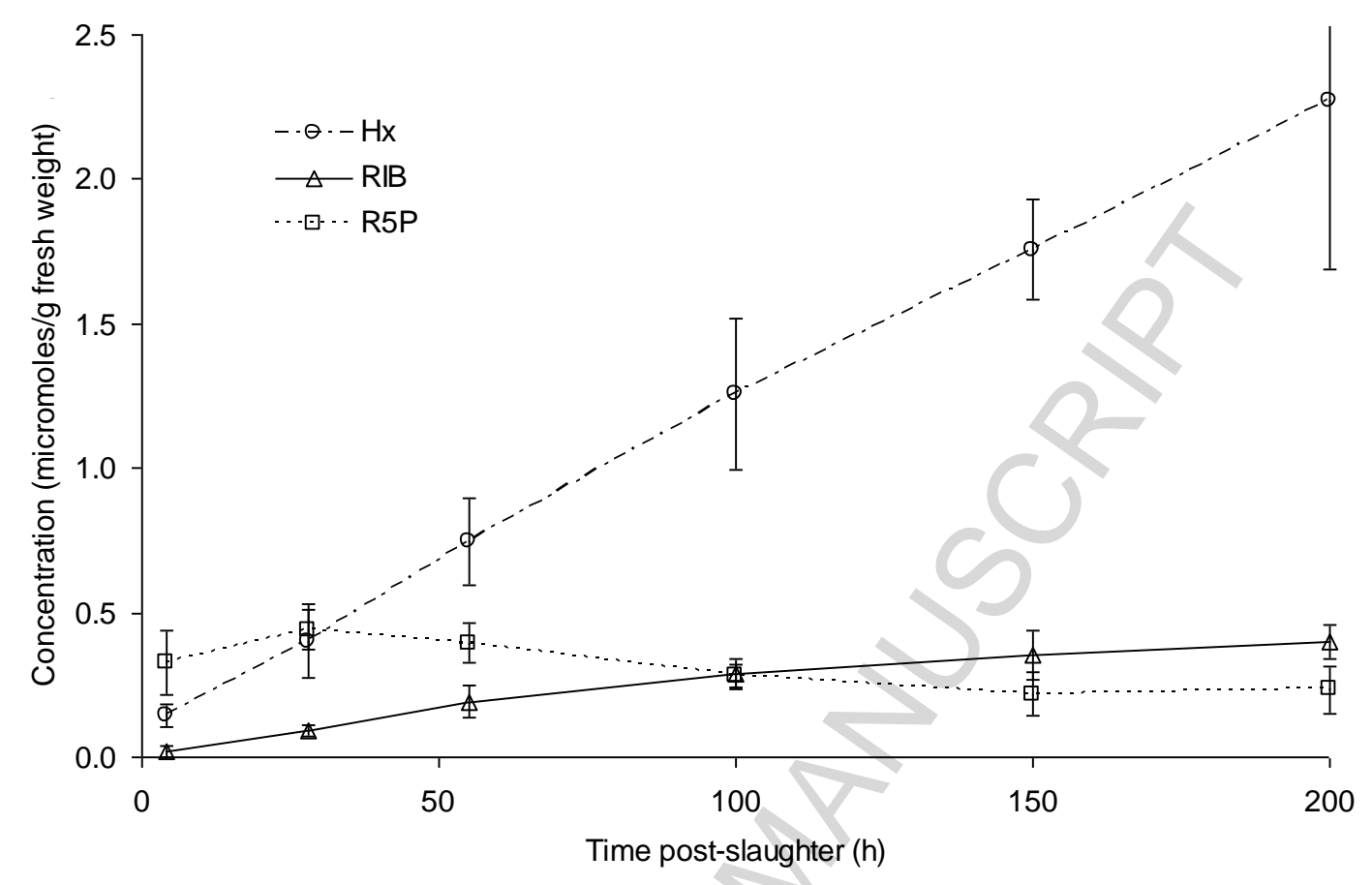


Figure 6:

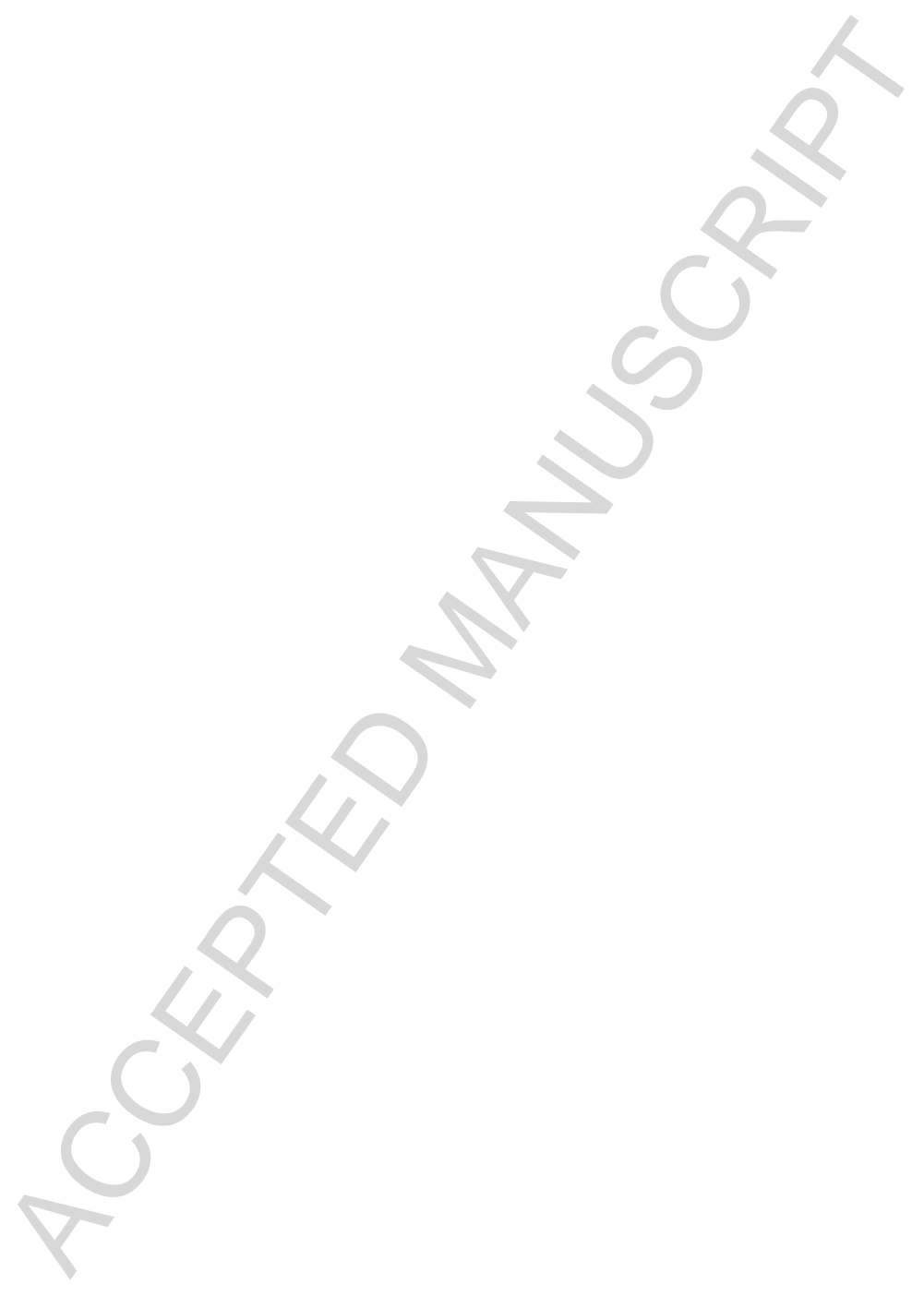

